\section{An Audit on the implementation of administering Ondansetron in children with acute gastroenteritis and its effect on admission rate}

\author{
Saskia D'Sa1*, Ahad Hussain², Mushtaq Hussain ${ }^{1}$, Zahir Afridi $^{1}$, \\ John Twomey ${ }^{1}$ and Irfan Ahmed ${ }^{1}$ \\ 'Department of Paediatrics and Neonatology, University Hospital, Limerick (UHL) and University \\ Maternity Hospital, Limerick, (UMHL), Ireland \\ ${ }^{2}$ School of Medicine (SoM), University of Limerick, Ireland
}

\section{Abstract}

Acute gastroenteritis (AGE) is a common presenting complaint in paediatrics. Most often, the reason for admission into hospital is to initiate intravenous rehydration in patients with severe dehydration and inability to tolerate oral intake. We found that Ondansetron acts as a potent antiemetic to support an increased number of children receiving oral hydration, and subsequently leading to decreased rates of admission. This study aims to audit the use of Ondansetron to Oral Rehydration Therapy (ORT) on children with acute gastroenteritis, and its effect on admission rates from the emergency department in University Hospital, Limerick (UHL). Data collected over a 3-month period from June to August 2017 in which Ondansetron was not used was compared to another 3-month period when Ondansetron was used. Several outcomes were measured including admission to hospital.

The rate of admission decreased by $15 \%$ [26/74 (35\%) in 2017 to $16 / 81(20 \%)$ in 2019 $p=0.22$ ]. 81 patients received Ondansetron, of which $79 \%$ were successfully rehydrated orally. The administration of Ondansetron reduced the need for intravenous fluids and hospital admission overall in these children with AGE. This reduction ultimately accounted for lower costs incurred by the Health Services Executive per patient, and also suggested the anti-emetic use as a cost effective measure for managing and treating patients with AGE.

\section{More Information}

*Address for Correspondence: Saskia D'Sa, Department of Paediatrics and Neonatology, University Hospital, Limerick (UHL) and University Maternity Hospital, Limerick1 (UMHL), Ireland, Tel: 07546636384; Email: saskia.dsa@gmail.com

Submitted: March 01, 2021

Approved: March 24, 2021

Published: March 25, 2021

How to cite this article: D'Sa S, Hussain A, Hussain M, Afridi Z, Twomey J, et al. An Audit on the implementation of administering Ondansetron in children with acute gastroenteritis and its effect on admission rate. J Adv Pediatr Child Health. 2021; 4: 023-026.

DOI: 10.29328/journal.japch.1001025

ORCiD: orcid.org/0000-0003-3016-9299

Copyright: ๑ 2021 D'Sa S, et al. This is an open access article distributed under the Creative Commons Attribution License, which permits unrestricted use, distribution, and reproduction in any medium, provided the original work is properly cited.

(D) Check for updates

OPEn ACCESs

\section{Introduction}

Acute Gastroenteritis (AGE) is a clinical syndrome associated with increased stool frequency, accompanied by vomiting, fever or abdominal pain [1]. It usually lasts between 1-to 2-weeks in length and is one of the most common presentations to the Emergency Department (ED). Our Paediatric ED at UHL sees approximately 2,000 children per year, out of which at least 500 visits are due to AGE. Majority of the complications associated with AGE are hypovolaemia, dehydration, electrolyte imbalances, and a small percentage can get lactose intolerances [2].

A common symptom is vomiting which can be distressing for families and the primary reason for complications such as dehydration and electrolyte imbalance [2]. To combat this complication of dehydration, treatment for these children is fluid repletion and maintaining hydration [3]. The preferred means of fluid repletion is through Oral Rehydration Therapy (ORT), which can vary between different countries [3]. The World Health Organization (WHO) recommends a solution with one-half teaspoon of salt with six-teaspoons of sugar in one litre of water, as this can be easily accessed in developing nations as a rehydration solution [3,4]. In Ireland, the practice of ORT is with one-sachet of Dioralyte solution dissolved in 200 millilitres (mls) of water (Table 1) [5]. However, in cases of severe dehydration where children cannot tolerate ORT, admission is usually required [3].

One of the principal factors in failure of ORT is due to vomiting, and measures to control it have been shown to promote the success rates with oral rehydration. There are 
Table 1: Composition of Dioralyte Solution versus WHO Oral Rehydration Solution $[4,5]$.

\begin{tabular}{|c|c|c|}
\hline $\begin{array}{c}\text { Electrolyte } \\
\text { Components }\end{array}$ & $\begin{array}{c}\text { WHO Oral Rehydration Solution } \\
\text { (mmol/L) }\end{array}$ & $\begin{array}{c}\text { Dioralyte Solution } \\
\text { (mmol/L) }\end{array}$ \\
\hline Sodium & 75 & 60 \\
\hline Chloride & 65 & 50 \\
\hline Potassium & 20 & 20 \\
\hline Glucose & 75 & 90 \\
\hline Citrate & 10 & 10 \\
\hline Osmolarity & $245(\mathrm{mOsm} / \mathrm{L})$ & $140(\mathrm{mOsm} / \mathrm{L})$ \\
\hline
\end{tabular}

various antiemetics available such as dopamine antagonists, anticholinergic agents, and antihistamines that have significant side effects, and hence have limited use for AGE in paediatrics. From previous studies, ondansetron has been identified as the ideal antiemetic which is a selective serotonergic 5-HT3 receptor antagonist and quickly absorbed when given orally [6]. Several clinical trials have been conducted to assess the effectiveness of antiemetics and ondansetron has concurrently shown increases in ORT tolerance; thus leading to a reduction in vomiting and decreased need for IV hydration for children with AGE $[1,6]$.

The purpose of this retrospective study is to only evaluate the effect of oral ondansetron in our ED on the admission rate of children with AGE during two separate study periods, and to discuss the benefits of this practice.

\section{Methods}

University Hospital Limerick (UHL) uses a centralized electronic system for tracking patients visiting the ED called MAXIMS. We used this system to look at children between the ages of 3 months to 16 years who presented to the ED with AGE.

The typical process for children entering our ED with AGE includes an initial assessment by a triage nurse, followed by a paediatric senior house officer or registrar taking a history and determining a plan of action to admit, observe or discharge the child home. Children with suspected AGE are assessed for their symptoms (i.e. diarrhoea, vomiting), blood glucose levels, level of consciousness, severity of dehydration, and bloods as necessary. These children are then observed in ED while undergoing ORT. Parents were provided with Dioralyte solution and children who failed the trial of ORT were given a single dose of ondansetron. ORT was recommenced after thirty minutes of ondansetron administration. The patients were reassessed for either discharge from ED after successful oral rehydration or admission to the hospital if they needed IV fluid administration. If any patient required IV hydration, they were admitted and not discharged from ED.

The initiation of the use of Ondansetron was determined by asking clinical nurse managers and consultants that were part of the commencement. This was determined to be 2017. Thereafter, the audit was initiated by use of our electronic database to search for symptoms of AGE such as "vomiting", "vomiting with-", and "diarrhea", "diarrhoea with-". Data collected included age, sex, weight, length of ED stay, documentation of ORT, blood investigations, use of Ondansetron and patient outcome over a 3-month period from June to August 2017. The same data was collected again from a more recent period of June to August 2019 when Ondansetron was a part of ORT protocol in our ED. Children who presented again within two weeks with symptoms of gastroenteritis were counted as a new case. Results were tested for significance using the T - test to obtain $p$ values.

\section{Results}

Baseline characteristics were compared with respect to patient age, sex and admission between the two periods (Figures 1,2). In 2019, there were a total of 81 patients who attended our ED with AGE over the three-month June to August period. In 2017, there were 74 patients for the same time-period. The average age of children in this group was 1 year to 6 years old, with a greater proportion of the patients being male in both sample groups (Figures 1,2). From the collected data, it was noted that children presenting in 2019 were younger compared to 2017. In 2017, majority of children presented between the ages of 4 to 6-years, whereas in 2019 the presentation was between the ages of 1 to 3-years. older children at ages 13-16 years were a much smaller population and rarely required admission after the initiation of Ondansetron in 2019.

In 2017, 48 children (65\%) completed a successful trial

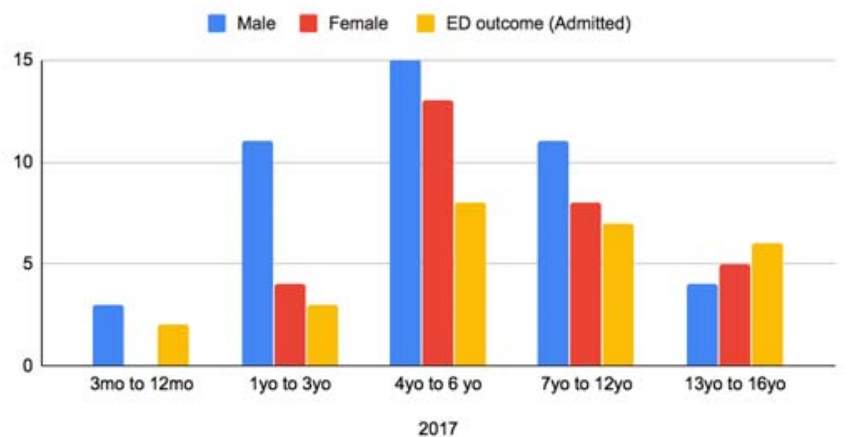

Figure 1: Distribution of patients Presenting to ED in 2017 with AGE - Age, sex and Admitted patients.

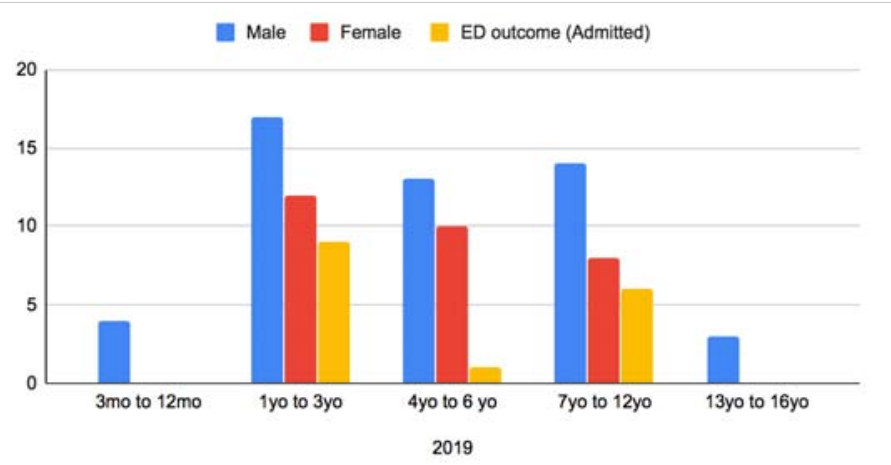

Figure 2: Distribution of patients Presenting to ED in 2019 with AGE - Age, sex and Admitted patients. 
of ORT and were discharged from ED. In 2019, 64 children (80\%) completed a successful ORT with ondansetron and were discharged from ED. All of the remaining 26 (in 2017) and 16 (in 2019) children received intravenous fluids and were admitted. Admission rates in 2017 were $35 \%$ of the attendees to ED, which reduced to $20 \%$ in 2019 within the same 3-month period (Figure 3). $\mathrm{T}$ - Test was run using the admitted patients in ED from 2017 and compared with the second group of admitted patients from 2019. Results from this were $p=0.22$.

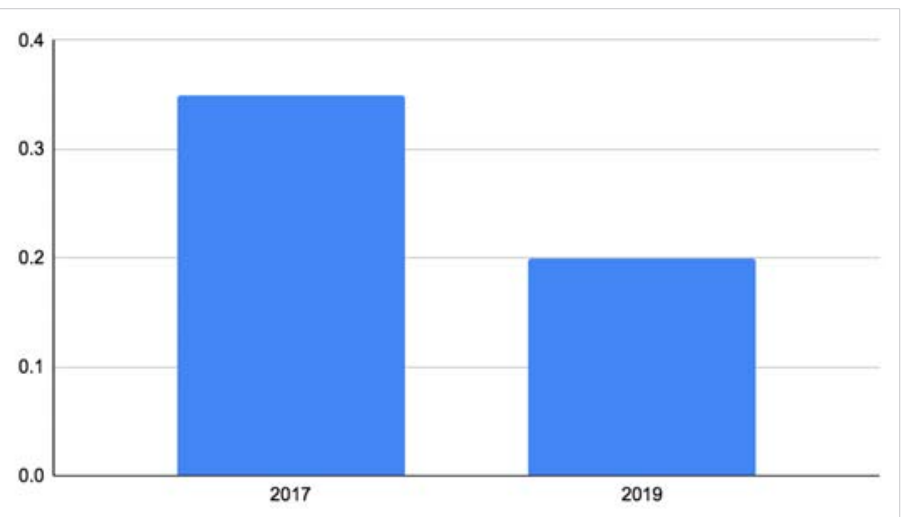

Figure 3: Number AGE admissions between the two years.

\section{Discussion}

It has been demonstrated that a single dose of Ondansetron to children with AGE increases success of oral rehydration. When children were given ORT after the use of Ondansetron, they were able to tolerate the fluid intake orally and thus suggesting that they would be able to recover at home with adequate fluids our data showed a $15 \%$ reduction in hospital admission and intravenous fluids administration in Ondansetron and ORT group (16 out of 81) as compared to year 2017 when Ondansetron was not used (26 out of 74 patients). The intervention is simple, well tolerated with a reduction in the rate of hospital admission between the two groups.

We believe that the reduction in hospital admissions has a two-fold benefit. Firstly, studies have previously identified hospitalization of children to be a frightening and stressprovoking experience for both parents and children. By decreasing hospital admissions, we are able to reduce social factors such as negative anxiety-provoking emotions that children may incur during their admission [2]. Through discharging children from ED, we are able to promote their management in a familiar and comfortable environment, leading to a potentially quicker recovery and decreased time away from school.

Secondly, our data when extrapolated over a 1-year period highlights a large decrease in hospital admissions which has significant cost implications. Not only does this promote economic benefits but can also lead to resource conservation. On average, our Irish HSE healthcare system spends approximately 1000 euros for any admitted patient in a single occupancy room, and 24-hour nursing care provision [3]. With AGE, we anticipate isolation precautions and singleroom occupancy, leading to increased resource utilization and cost. If admissions could be avoided and children discharged from the ED, it would be immensely cost effective.

Parental expectations, level of staffing, medical staff initiatives and acceptance for ORT, difficulties in IV cannulation and fear of masking any underlying illness are usual barriers for promotion of ORT in ED departments. We found that the administration of oral ondansetron to facilitate ORT in our ED is useful in managing children with AGE and vomiting. The recorded data did not highlight the use of any additional antiemetics apart from ondansetron. It improves the tolerance and adherence to ORT in the ED and reduces the rate of intravenous fluid use and hospital admission.

Limitations from this study that may have affected the statistical testing could have been due to individual usage of the online MAXIMS system in ED. Other issues could stem from a smaller sample size overall. We do strongly believe that the reduction in the admission rates from 2017 to 2019 have been strongly affected by the usage of Ondansetron.

\section{Conclusion}

AGE is one of the most common presenting complaints in the paediatric emergency room. Patients are usually admitted due to poor oral intake and need for intravenous hydration. Use of Ondansetron has been found to significantly decrease admissions, which ultimately will result in social benefits and decreased costs associated with admissions. Furthermore, it will be crucial to see the employment of Ondansetron strictly amongst all non-consultant hospital doctors (NCHDs) to promote a more economic outcome for a financially stretched health care system.

\section{Declarations}

Compliance with ethical standards: As a quality improvement and retrospective study, this study did not require any ethical approval. This article does not contain any studies with direct human participants performed by any of the authors.

\section{References}

1. Rokach A. Psychological, emotional and physical experiences of hospitalized children. Clin Case Rep Rev. 2016; 2: 399-401.

2. Ryan MG, Edwards MS, Torchia MM. Acute viral gastroenteritis in children in resource-rich countries. UpToDate. 2020.

3. Hartman S, Brown E, Loomis E, Russell HA. Gastroenteritis in Children. American Academy of Family Physicians. https://www.aafp.org/afp/2019/0201/p159.pdf

4. World Health Organization. The Treatment of Diarrhoea - A Manual for Physicians and other senior health care workers. Department of Child and Adolescent Health Development. 2005. https://apps.who. int/iris/bitstream/handle/10665/43209/9241593180.pdf?sequence=1 
5. Dioralyte Relief Blackcurrant Sachets P. (n.d.). 2020. https://www.medicines.org.uk/emc/product/274/smpc

6. Sturm JJ, Hirsh DA, Schweickert A, Massey R, Simon HK Ondansetron use in the Pediatric Emergency Department and effects on hospitalisation and return rates: are we masking alternate diagnoses? Ann Emerg Med. 2010; 55: 415-422. PubMed: https://pubmed.ncbi.nlm.nih.gov/20031265/

7. Das JK, Kumar R, Salam RA, Freedman S, Bhutta ZA. The effect of antiemetics inchildhood gastroenteritis. BMC publichealth. 2013;13:S9. PubMed: https://www.ncbi.nlm.nih.gov/books/NBK174828/

8. Health Services Executive. Hospital Charges- Acute Hospitals Division. 2020. https://www.hse.ie/eng/about/who/acute-hospitalsdivision/patient-care/hospital-charges/
9. Marchetti F, Bonati M, Maestro A, Zanon D, Rovere F, et al. Oral Ondansetron versus Domperidone for Acute Gastroenteritis in Pediatric Emergency Departments: Multicenter Double Blind Randomized Controlled Trial. PloS One. 2016; 11: e0165441. PubMed: https://pubmed.ncbi.nlm.nih.gov/27880811/

10. Mullarkey C, Crowley E, Martin C. The addition of ondansetron to a oral rehydration protocol for children with acute gastroenteritis. Irish Med J. 2013. http://hdl.handle.net/10147/303572

11. World Health Organization. Oral Rehydration Salts - Production of the new ORS. Department of Child and Adolescent Health and Development (CAH) World Health Organization. 1998. https://apps.who.int/iris/bitstream/handle/10665/69227/WHO_FCH_ CAH_06.1.pdf?sequence=1 